\title{
Relação potássio-nitrogênio para o diagnóstico e manejo nutricional da cultura da batata
}

\author{
Clarissa Melo Cogo( ${ }^{(1)}$, Jerônimo Luiz Andriolo( ${ }^{(1)}$, Dilson Antônio Bisognin ${ }^{(1)}$, Rodrigo dos Santos Godoi ${ }^{(1)}$, \\ Orcial Ceolin Bortolotto ${ }^{(1)}$ e Gean Lopes da LuZ ${ }^{(1)}$
}

(1)Universidade Federal de Santa Maria, Dep. de Fitotecnia, Camobi, CEP 97105-900 Santa Maria, RS. E-mail: andriolo@smail.ufsm.br, dilsonb@smail.ufsm.br

\begin{abstract}
Resumo - O objetivo deste trabalho foi determinar a curva máxima de diluição do K e ajustar a relação com a curva de diluição do $\mathrm{N}$, durante o ciclo de crescimento e desenvolvimento da batata, para fins de diagnóstico e manejo nutricional. Os tratamentos consistiram de soluções nutritivas com concentrações de K de 3,5; 5,5; 6,5; 8,0 e 9,5 mmol L-1 . O delineamento experimental inteiramente casualizado foi empregado com quatro repetições. Quatro plantas de cada tratamento foram coletadas, em intervalos semanais, para análise do crescimento e determinação dos teores de $\mathrm{N}$ e K. A curva máxima de diluição do K foi ajustada e a extração máxima foi determinada durante o ciclo de crescimento e desenvolvimento da cultura. Observou-se que a estimativa dos teores máximos de K pode ser obtida a partir dos teores críticos de $\mathrm{N}$. As quantidades de K a serem fornecidas, para obtenção de determinada produtividade, podem ser estimadas com base no teor de $\mathrm{N}$ nos tecidos.
\end{abstract}

Termos para indexação: Solanum tuberosum, diluição, nutrição mineral, adubação.

\section{Nitrogen-potassium relationship for diagnosis of plant nutritional status and fertilization of the potato crop}

\begin{abstract}
The objective of this work was to determine the maximum K dilution curve and the relationship with the $\mathrm{N}$ dilution curve, during growth and development of the potato crop, for nutritional diagnosis and fertilization purposes. Treatments consisted of nutrient solutions with K concentrations of 3.5, 5.5, 6.5, 8, and 9.5 mmol L-1. The completely randomized experimental design was adopted with four replications. Four plants were harvested, at weekly intervals, to quantify plant growth and to determine $\mathrm{N}$ and $\mathrm{K}$ tissue concentrations. The maximum $\mathrm{K}$ dilution curve was adjusted, and the maximum K uptake was determined, during crop growth and development. It was observed that maximum K concentrations might be estimated from critical $\mathrm{N}$ concentrations. Quantities of $\mathrm{K}$ fertilizers to be supplied to achieve a pre-fixed crop yield can be estimated from tissue $\mathrm{N}$ concentration.

Index terms: Solanum tuberosum, dilution, mineral nutrition, fertilization.
\end{abstract}

\section{Introdução}

Elevadas doses de fertilizantes são empregadas na cultura da batata. A exportação de K nos tubérculos é 1,5 vez maior do que a do $\mathrm{N}$ e de quatro a cinco vezes maior do que a do P (Yorinori, 2003). O K é importante para a translocação de açúcares e síntese de amido (Reis Junior \& Fontes, 1996), o que afeta a produtividade e a qualidade dos tubérculos (Westermann et al., 1994a, 1994b). As indicações de adubação potássica para a cultura da batata, no Rio Grande do Sul, para produtividade acima de $20 \mathrm{tha}^{-1}$, com teores de $\mathrm{K}$ no solo muito alto e muito baixo, são de 140 e $220 \mathrm{~kg} \mathrm{ha}^{-1}$ de $\mathrm{K}_{2} \mathrm{O}$, respectivamente (Sociedade Brasileira de Ciência do Solo, 2004).
Na região Sul do Brasil são realizados dois cultivos anuais, conhecidos como safra e safrinha, em solos com teores elevados de K. Em cada cultivo, é efetuada a adubação da cultura, e o acúmulo desse nutriente pode ocorrer ao longo dos anos. Embora o K seja exigido em alta quantidade, quando em dose excessiva pode reduzir a produção de tubérculos, por interferir no equilíbrio eletroquímico das células, o que afeta a absorção e a

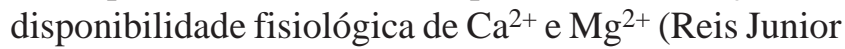
et al., 1999).

As atuais indicações de adubação para a cultura da batata estão baseadas unicamente na análise de solo. A exportação de $K$ varia em função da produção de matéria seca, do índice de colheita e de fatores ambientais 
que interferem nos processos de crescimento e absorção mineral (Fontes, 2001). Por esse motivo, métodos que levem em conta o teor de nutrientes nos tecidos da planta, devem também ser empregados para maximizar a eficiência de uso da adubação.

O N é o elemento para o qual os métodos indiretos de diagnóstico nutricional estão mais desenvolvidos, especialmente a determinação in situ do teor de clorofila das folhas. Para esse nutriente, a concentração crítica (Nc) representa o teor a partir do qual a resposta no crescimento deixa de ser observada, enquanto a concentração máxima $(\mathrm{Nm})$ representa o teor máximo, acima da Nc, que pode ser encontrado nos tecidos da planta (Fontes, 2001).

$\mathrm{O}$ teor de clorofila das folhas pode ser relacionado diretamente com a curva crítica de diluição de $\mathrm{N}$, durante o ciclo de crescimento e desenvolvimento, o que permite diagnósticos diretamente na lavoura. No caso da batata, a curva crítica de diluição de $\mathrm{N}$ (Nc) foi previamente ajustada para diferentes cultivares e condições ambientais (Greenwood et al., 1990; Bélanger et al., 2001). Para a cultivar Asterix, no Sul do Brasil, Paula (2005) ajustou equações para a curva crítica de diluição e para a extração de $\mathrm{N}$, tendo considerado a produtividade da cultura. No caso do K, existem indicações na literatura sobre teores nos órgãos da planta, associados a determinados índices de produtividade (Fontes et al., 1996; Reis Junior \& Monnerat, 2001; Yorinori, 2003). Porém, esses teores foram obtidos a partir de diferentes doses de adubação potássica aplicadas ao solo e não traduzem a dinâmica de absorção, em relação ao acúmulo de matéria seca da cultura. Resultados sobre as curvas de diluição e das concentrações máxima (Km) e crítica (Kc) do K, para essa cultura, não estão disponíveis na literatura.

Para explicar a absorção do K durante o ciclo de crescimento e desenvolvimento das plantas, Greenwood \& Stone (1998) estenderam para esse nutriente o modelo de diluição do $\mathrm{N}$ descrito por Lemaire et al. (1997) que está baseado no crescimento e partição da matéria seca entre um compartimento metabólico, formado pelas folhas, e um compartimento estrutural ou de armazenamento. Os teores e a absorção do $\mathrm{N}$ são estimados por meio da dinâmica de crescimento desses dois compartimentos. Greenwood \& Stone (1998) aplicaram o modelo para o K, sob a hipótese de que sua concentração decresce com o aumento da biomassa das culturas e mantém uma relação de proporcionalidade com a concentração crítica de N. Os autores validaram o modelo ao empregar resultados de experimentos com 16 espécies de hortaliças e confirmaram a existência dessa relação, tanto para a concentração crítica quanto para concentração máxima de K. Essa validação, no entanto, não foi feita para a cultura da batata.

O objetivo deste trabalho foi determinar a curva máxima de diluição do $\mathrm{K}$, ajustar a relação com a curva de diluição do $\mathrm{N}$, durante o ciclo de crescimento e desenvolvimento da cultura, e fazer inferências sobre o emprego de uma relação simples entre esses dois nutrientes no manejo da adubação da cultura da batata.

\section{Material e Métodos}

O trabalho foi realizado em abrigo telado de $200 \mathrm{~m}^{2}$, do Dep. de Fitotecnia da Universidade Federal de Santa Maria (UFSM). Sacolas de polietileno de $4 \mathrm{dm}^{3}$, com 1,4 kg de substrato orgânico (PlantmaxHA) foram dispostas sobre calhas revestidas com polietileno duplaface, de coloração branca (100 $\mu \mathrm{m}$ de espessura), com a declividade de $1 \%$. As sacolas foram dispostas em um arranjo de $1 \mathrm{~m}$ entre linhas e $0,30 \mathrm{~m}$ entre sacolas.

A análise química do substrato foi efetuada no Lab. de Análise de Solos da UFSM, conforme Tedesco et al. (1995), e indicou teores disponíveis de 95, 1.506, 7.831 e $2.948 \mathrm{mg} \mathrm{kg}^{-1} \mathrm{de}$ P, K, Ca e Mg, respectivamente. Um tubérculo da cultivar Asterix foi plantado em cada sacola, no dia 28 de agosto de 2004. As plantas foram tutoradas com tela plástica de malha de $0,10 \mathrm{~m}$, instalada a $0,25 \mathrm{~m}$ acima das sacolas.

Os tratamentos foram constituídos por cinco soluções nutritivas, com concentrações de K de 3,5 (T1), 5,5 (T2), 6,5 (T3), 8 (T4) e $9,5 \mathrm{mmol} \mathrm{L}^{-1}$ (T5). Os demais nutrientes foram fornecidos nas concentrações: $13 \mathrm{mmol} \mathrm{L}^{-1}$ de $\mathrm{NO}_{3}{ }^{-} / \mathrm{NH}_{4}{ }^{+} ; 2$ mmol L${ }^{-1}$ de $\mathrm{H}_{2} \mathrm{PO}_{4}^{-}$; $1 \mathrm{mmol} \mathrm{L}^{-1}$ de $\mathrm{SO}_{4}{ }^{2-;} ; \mathrm{mmol} \mathrm{L}^{-1}$ de $\mathrm{Mg}^{2+} ; 2 \mathrm{mmol} \mathrm{L}^{-1}$ de $\mathrm{Ca}^{2+}$; 0,03 $\mathrm{mg} \mathrm{L}^{-1}$ de Mo; 0,26 $\mathrm{mg} \mathrm{L}^{-1}$ de B; 0,06 $\mathrm{mg} \mathrm{L}^{-1}$ de Cu; 0,50 mg L-1 de Mn; 0,22 $\mathrm{mg} \mathrm{L}^{-1}$ de Zn e $4 \mathrm{mg} \mathrm{L}^{-1}$ de Fe. Os fertilizantes empregados foram o nitrato de potássio, sulfato de potássio, nitrato de cálcio (calcinit), nitrato de amônio, monofosfato de potássio e sulfato de magnésio.

O cálculo do equilíbrio eletroquímico dos macronutrientes e das quantidades de sais micronutrientes foi feito de acordo com Andriolo (1999). A condutividade elétrica da solução nutritiva foi de 1,7; 1,$87 ; 2,19 ; 2,51$ e $2,72 \mathrm{dS} \mathrm{m}^{-1}$, respectivamente, para T1, T2, T3, T4 e T5. 
$\mathrm{O}$ pH foi mantido entre os limites de 5,3 e 6,0. As soluções nutritivas foram fornecidas diariamente por meio de tubos gotejadores, em sistema aberto e com drenagem perdida. Empregou-se um gotejador de vazão igual a 1,4 $\mathrm{L} \mathrm{h}^{-1}$, para cada sacola, e um coeficiente de drenagem de 20\% (Andriolo, 1999). Após cada fertirrigação, os volumes drenados na extremidade inferior da calha foram recolhidos e medidos. A diferença entre o volume fornecido e drenado foi considerada como volume retido em cada sacola. A freqüência diária das fertirrigações foi ajustada à demanda hídrica da cultura, estimada com base na radiação solar e na área foliar de hortaliças cultivadas no mesmo local, em ambiente protegido (Dalsasso et al., 1997). O volume de solução nutritiva retida para cada planta, no decorrer do período experimental, totalizou 6,7 L por planta, correspondente a 912,3, 1.433,7, 1.694,3, 2.085,3 e 2.476,3 mg por planta de $\mathrm{K}$, para cada tratamento.

O delineamento experimental inteiramente casualizado foi empregado, com quatro repetições de uma fileira com 25 sacolas. As plantas bordaduras entre parcelas e entre plantas, de diferentes coletas, não foram empregadas para efetuar determinações.

A partir dos 32 dias após o plantio, foram coletadas, em intervalos semanais, quatro sacolas com plantas de cada tratamento para análise do crescimento. Imediatamente após a coleta, foram separados os limbos foliares, pecíolos e hastes e tubérculos, e foi determinada a massa de matéria fresca. Para a obtenção da massa de matéria seca, essas frações foram colocadas em estufa de circulação forçada de ar, à temperatura de $60^{\circ} \mathrm{C}$, até massa constante. A massa de matéria seca total foi obtida pela soma dessas frações. O experimento foi encerrado aos 73 dias após o plantio, quando foi constatado o início da senescência das plantas.

Amatéria seca foi moída em moinho tipo Wiley. Os teores de $\mathrm{K}$ foram determinados por espectrofotometria de chama, e os de nitrogênio pelo método Kjeldahl, conforme descrito por Tedesco et al. (1995). Os teores dos nutrientes na matéria seca foram empregados para ajustar os coeficientes do modelo de diluição do N (Lemaire et al., 1997) e do K (Greenwood \& Stone, 1998), por meio da seguinte equação: $\mathrm{N} / \mathrm{K}\left(\right.$ dag kg$\left.^{-1}\right)=$ a MS-b , em que N/K representa a concentração de $\mathrm{N}$ ou de K; MS é a massa de matéria seca da parte aérea, em tha ${ }^{-1}$; a e b são coeficientes de ajuste. A estimativa das quantidades de cada nutriente extraídas pelas culturas com massa de matéria seca acumulada da parte aérea igual ou superior a $1 \mathrm{t} \mathrm{ha}^{-1}$ foi obtida por meio da equação transformada: $\mathrm{N} / \mathrm{K}\left(\mathrm{kg} \mathrm{ha}^{-1}\right)=10 \mathrm{a} \mathrm{MS}(1-\mathrm{b})$.

\section{Resultados e Discussão}

Não foram observadas diferenças significativas nas concentrações de K na matéria seca em plantas inteiras, nas coletas efetuadas durante o ciclo de crescimento e desenvolvimento, nos cinco tratamentos. Esses resultados permitem ajustar uma única curva, que representa a curva máxima de diluição do K (Figura 1), uma vez que foram utilizadas as concentrações máximas possíveis para a cultivar Asterix.

Os dados entre coletas periódicas ajustaram-se ao mesmo modelo potencial, empregado por outros autores, para explicar a diluição do $\mathrm{N}$ durante o ciclo da cultura da batata (Greenwood et al., 1990; Bélanger et al., 2001; Paula, 2005). Uma única curva de diluição foi ajustada com os resultados de todos os tratamentos, com $\mathrm{K}\left(\mathrm{dag} \mathrm{kg}^{-1}\right)=5,54 \mathrm{MS}^{-0,317}$ e r $^{2}=0,90$. A concentração de K estimada pela equação, nas fases iniciais do ciclo de desenvolvimento, foi de 5,54 dag $\mathrm{kg}^{-1}$. Essa concentração foi $11,9 \%$ superior àquela obtida pela aplicação do modelo potencial de diluição, nos resultados de Yorinori (2003) para a cultivar Atlantic, que foi de 4,95 dag kg-1. A intensidade da diluição, representada pelo coeficiente $\beta$ igual a $-0,317$, foi menos acentuada

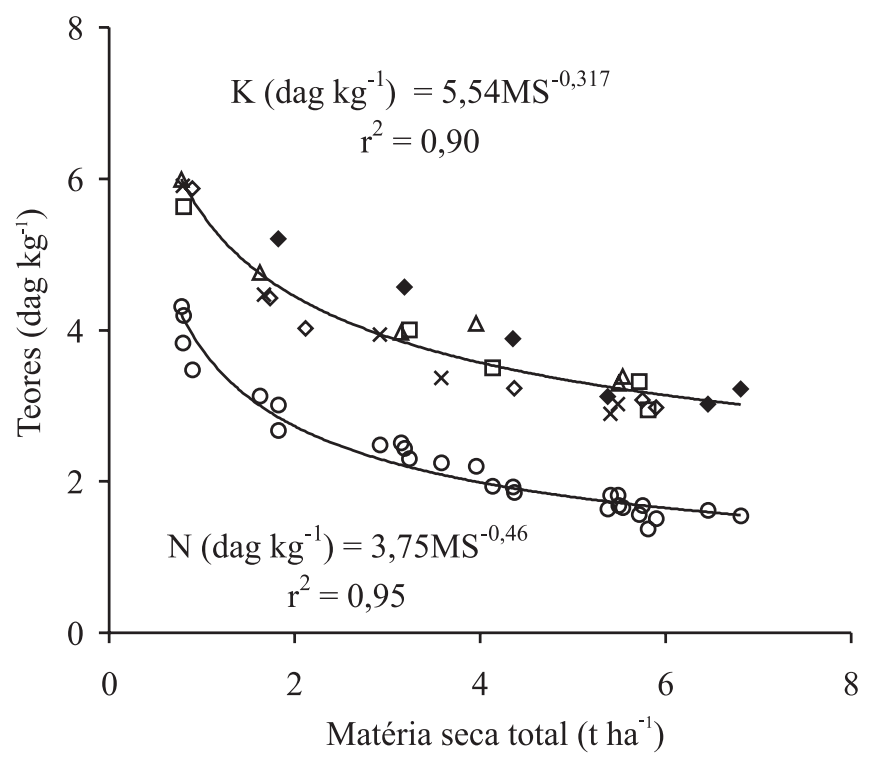

Figura 1. Teores observados de $\mathrm{N}$ e de $\mathrm{K}$ na matéria seca (MS) da planta inteira, durante o crescimento de plantas de batata cultivadas em solução nutritiva com seis níveis de

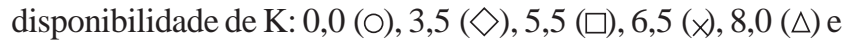
$9,5 \mathrm{mmol} \mathrm{L}^{-1}(\diamond)$. 
do que aquela relativa aos resultados de Yorinori (2003), cujo valor foi de $-0,40$.

Os resultados da concentração de $\mathrm{N}$ também se ajustaram ao modelo potencial, sem diferir significativamente da curva crítica de diluição ajustada anteriormente por Paula (2005) para a mesma cultivar, no mesmo local (Figura 1). Isso significa que as quantidades de $\mathrm{N}$, fornecidas pela solução nutritiva, foram suficientes para atender à demanda de $\mathrm{N}$ necessária à produtividade potencial da cultura, em todos os tratamentos.

Uma relação linear foi ajustada entre os teores de $\mathrm{K}$ e $\mathrm{N}$ na planta inteira, durante todo o ciclo da cultura, que indicou que o acúmulo desses dois nutrientes obedece a uma relação simples de proporcionalidade (Figura 2). A concentração de $\mathrm{N}$ pode ser empregada como variável independente, para estimar tanto a concentração de $\mathrm{K}$ necessária na planta, quanto as quantidades a serem fornecidas pela adubação, por meio das equações do modelo de diluição.

$\mathrm{O}$ teor de $\mathrm{K}$ nas folhas não demonstrou relação com o acúmulo de matéria seca das plantas, nos tratamentos com as menores disponibilidades (T1, T2 e T3) (Figura 3 A). Entretanto, o teor aumentou em T4 e T5. Tendência oposta foi observada nas hastes e tubérculos, onde os teores diminuíram linearmente, à medida que avançou o ciclo de crescimento e desenvolvimento das plantas (Figura 3 B). Nesses dois órgãos, não foram observadas diferenças significativas entre os tratamentos. Os teores de $\mathrm{K}$ foram 2,2 vezes maiores nas hastes do que nos tubérculos.

A diluição do K em plantas de batata, no decorrer do ciclo de crescimento e desenvolvimento, seguiu o modelo potencial descrito para o N por Paula (2005). O fato de os dois nutrientes se ajustarem a um modelo de diluição similar pode ser atribuído às funções fisiológicas dos dois nutrientes no metabolismo das plantas. Enquanto o $\mathrm{N}$ está associado, principalmente, com a síntese de proteínas e clorofila, o K é o principal regulador iônico, que afeta, entre outros processos, a ativação das enzimas, o transporte de solutos, os tropismos e a abertura e fechamento dos estômatos. Isso significa que esses dois nutrientes concentram-se em órgãos com elevada atividade metabólica, a qual está associada ao crescimento, à diferenciação e aos mecanismos de regulação (Greenwood \& Stone, 1998; Shabala, 2003).

Na planta inteira, os teores representaram o resultado ponderal do produto entre o teor nos tecidos de cada órgão e a fração representada por esses órgãos na composição da matéria seca total da planta. A diluição no decorrer do ciclo da cultura foi determinada pelo metabolismo e, também, pelas relações de competição que regem a partição da matéria seca entre os órgãos da planta. Nas fases iniciais do ciclo de crescimento e desenvolvimento, as folhas e hastes constituíram os principais drenos na planta, com teores máximos de K, respectivamente, de 4,3 e 10,4 dag kg-1 (Figura 3 A e B). Nas fases finais, os tubérculos representaram aproximadamente $80 \%$ da massa de matéria seca total, com teores máximos de $\mathrm{K}$ de 2,5 dag kg-1

Os teores de $\mathrm{N}$, empregados para estabelecer a relação N/K, confirmaram também a curva crítica de diluição do $\mathrm{N}$, ajustada anteriormente para a mesma cultivar por Paula (2005). Para esse nutriente, são disponíveis métodos indiretos de diagnóstico, baseados no teor de clorofila e na reflexão/irradiação da cobertura vegetal, os quais oferecem maior rapidez que as análises químicas (Fontes, 2001). Além disso, o diagnóstico pode ser feito diretamente na lavoura, como ferramenta da agricultura de precisão. Uma vez concluída a diagnose do $\mathrm{N}$, a diagnose do $\mathrm{K}$ poderá ser estimada por meio da relação ajustada.

Pôde-se estimar as quantidades de N e K extraídas, para atingir determinado nível de produtividade de tubérculos, por meio das equações do modelo (Tabela 1). Neste trabalho, estas estimativas foram feitas, tendo-se considerado que os tubérculos detêm um teor de matéria

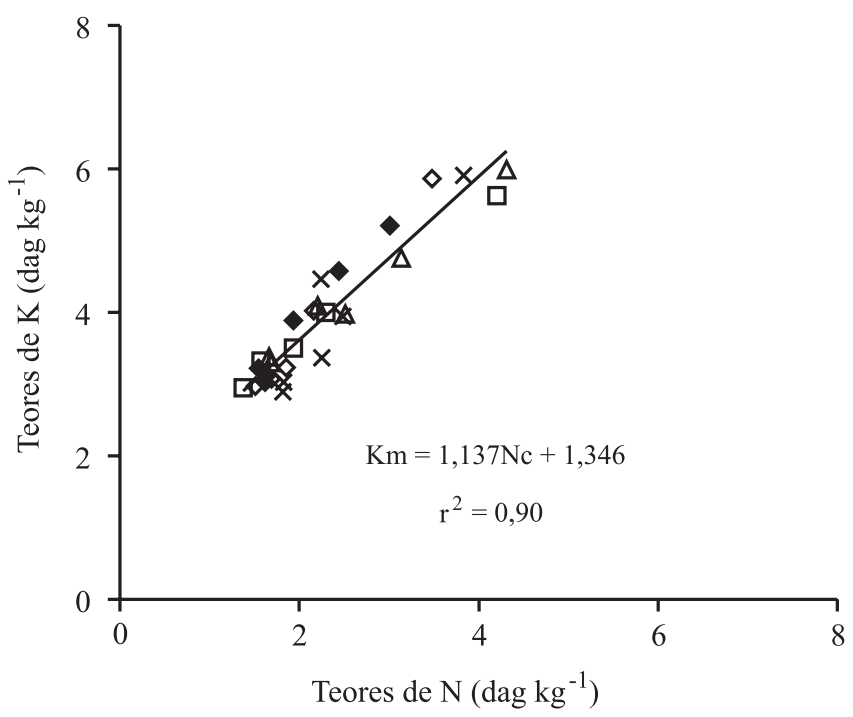

Figura 2. Relação entre as concentrações de $\mathrm{N}$ e de K na matéria seca (MS) da planta inteira, durante o crescimento de plantas de batata cultivadas em solução nutritiva com cinco níveis de disponibilidade de $\mathrm{K}: 3,5(\diamond), 5,5(\square), 6,5(\times), 8,0(\triangle)$ e $9,5 \mathrm{mmol} \mathrm{L}^{-1}(\diamond)$. 

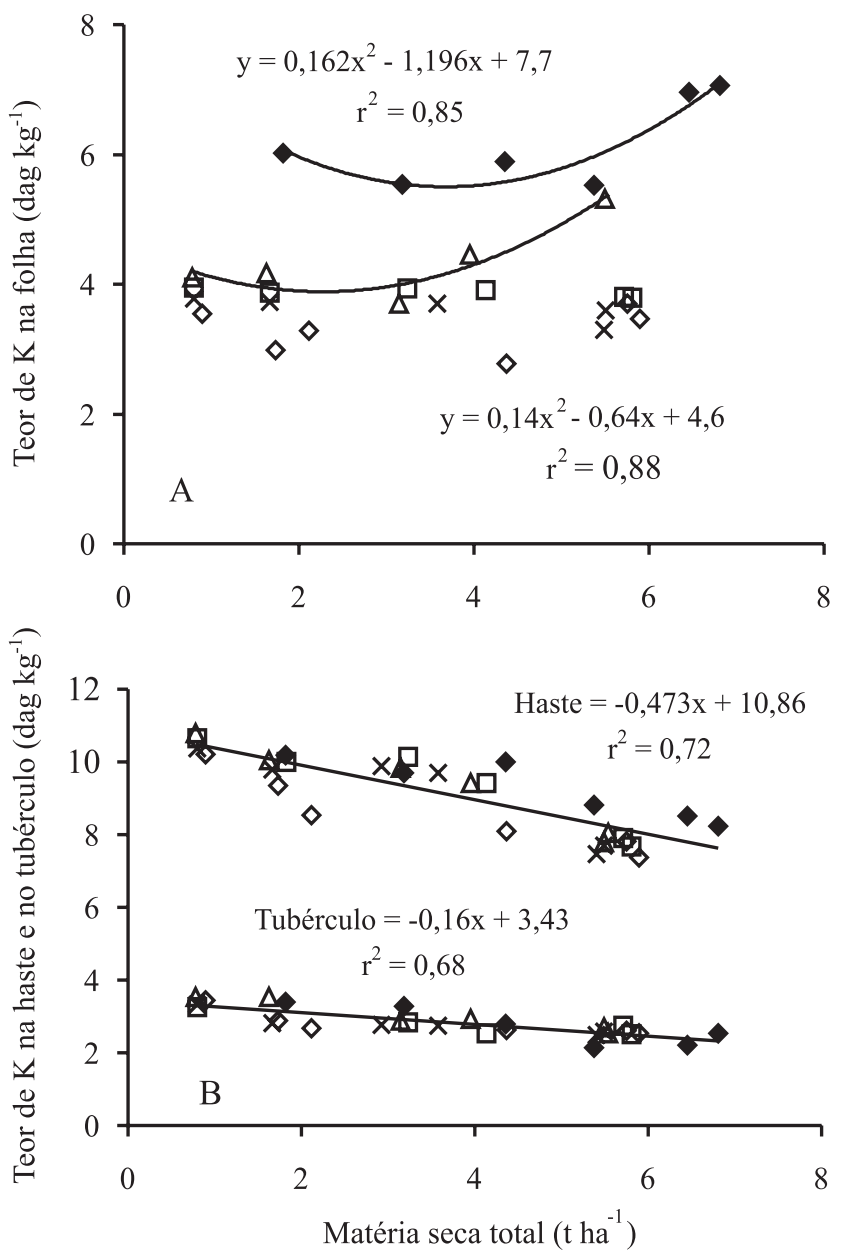

Figura 3. Teores de N e de K na matéria seca (MS) de folhas (A), hastes e tubérculos (B), durante o crescimento de plantas de batata cultivadas em solução nutritiva com cinco níveis de

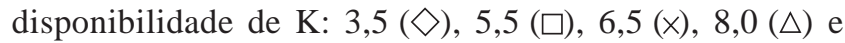
9,5 mmol L-1

Tabela 1. Quantidades extraídas de N e de K, estimadas pelas equações $N\left(\mathrm{~kg} \mathrm{ha}^{-1}\right)=37,5$ (MS) ${ }^{0,54}$ (Lemaire et al., 1997) e $\mathrm{K}\left(\mathrm{kg} \mathrm{ha}^{-1}\right)=55,4(\mathrm{MS})^{0,683}$, para diferentes níveis de produtividade da cultivar Asterix de batata.

\begin{tabular}{cccc}
\hline $\begin{array}{c}\text { Produtividade de } \\
\text { tubérculos }\left(\mathrm{t} \mathrm{ha}^{-1}\right)\end{array}$ & $\begin{array}{c}\text { Matéria seca } \\
\text { total }\left(\mathrm{t} \mathrm{ha}^{-1}\right)\end{array}$ & \multicolumn{2}{c}{ Quantidades extraídas $\left(\mathrm{kg} \mathrm{ha}^{-1}\right)$} \\
\cline { 3 - 4 } & 3,6 & 75,06 & Nitrogênio \\
20 & 4,8 & 87,71 & 136,37 \\
25 & 6,0 & 98,97 & 160,97 \\
30 & 7,2 & 109,24 & 187,35 \\
35 & 8,4 & 118,74 & 212,08 \\
40 & 9,6 & 127,65 & 235,52 \\
45 & 10,8 & 136,05 & 257,90 \\
50 & 12,0 & 144,04 & 279,41 \\
55 & 13,2 & 151,66 & 300,16 \\
60 & 14,4 & 158,98 & 320,26 \\
\hline
\end{tabular}

seca de $20 \%$ e acumulam $80 \%$ da matéria seca total da planta (Paula, 2005; Cogo et al., 2006). No caso de outros genótipos de batata, ajustes poderão ser necessários, levando-se em conta principalmente a partição da matéria seca entre a parte aérea e os tubérculos.

Com o emprego das equações do modelo de diluição, obteve-se a quantidade extraída de $1,9 \mathrm{~kg}$ de $\mathrm{K}$, para cada unidade de $\mathrm{N}$ extraído pela cultura (Tabela 1). Essa quantidade é 26,6\% superior àquela determinada por Yorinori (2003). A extração máxima de K, para atingir a produtividade de tubérculos de $33 \mathrm{t} \mathrm{ha}^{-1}$, foi de $226 \mathrm{~kg}$ de $\mathrm{K}_{2} \mathrm{O}$ por hectare. Essa quantidade é 61,4\% superior à dose de adubação potássica recomendada pela Sociedade Brasileira de Ciência do Solo (2004), que é de $140 \mathrm{~kg} \mathrm{ha}^{-1}$, para solos com teores muito altos desse nutriente. Isso significa que o manejo atual da adubação da cultura da batata, nessa região, deve ser ajustado aos níveis de produtividade, a fim de evitar o esgotamento da fertilidade do solo.

\section{Conclusão}

As quantidades de nitrogênio e potássio a serem fornecidas pela adubação da cultura da batata podem ser estimadas por meio de uma relação simples de proporcionalidade entre a curva máxima de diluição do potássio e a curva crítica de diluição do nitrogênio.

\section{Agradecimentos}

A Luís Francisco Finamor, do Lab. de Análises Químicas, do Dep. de Solos, da UFSM, pela realização das análises minerais; à Fapergs, pelo auxílio financeiro ao projeto de pesquisa e pela concessão de bolsa.

\section{Referências}

ANDRIOLO, J.L. Fisiologia das culturas protegidas. Santa Maria: UFSM, 1999. 142p.

BÉLANGER, G.W.J.R.; RICHARDS, J.E.; MILBURN, P.H.; ZIADI, N. Critical nitrogen curve and nitrogen nutrition index for potato in eastern Canada. American Journal of Potato Research, v.78, p.355-364, 2001.

COGO, C.M.; ANDRIOLO, J.L.; BISOGNIN, D.A.; GODOI, R. dos S.; BORTOLOTTO, O.C.; BARROS, G.T. Crescimento, produtividade e qualidade de processamento de tubérculos de batata produzidos sob alta disponibilidade de potássio. Ciência Rural, v.36, p.985-988, 2006.

DALSASSO, L.C.M.; HELDWEIN, A.; BURIOL, G.A.; SCHNEIDER, F.M.; STRECK, N.A.; DUCHÈNNE, T.; MACHET, J.M.; MARTIN, M. Potatoes. In: LEMAIRE, G. (Ed.). Diagnosis 
of the nitrogen status in crops. Berlin: Springer-Verlag, 1997. p.119130.

FONTES, P.C.R. Diagnóstico do estado nutricional das plantas. Viçosa: UFV, 2001. 122p.

FONTES, P.C.R.; REIS JUNIOR, R.A.; PEREIRA, P.R.G. Critical potassium concentration and potassium/calcium plus magnesium ratio in potato petioles associated with maximum tuber yields. Journal of Plant Nutrition, v.19, p.657-667, 1996.

GREENWOOD, D.J.; LEMAIRE, G.; GOSSE, G.; CRUZ, P.; DRAYCOTT, A.; NEETESON, J.J. Decline in N percentage of $\mathrm{C}_{3}$ and $\mathrm{C}_{4}$ crops with increasing plant mass. Annals of Botany, v.66, p.425-436, 1990.

GREENWOOD, D.J.; STONE, D. Prediction and measurement of the decline in the critical-K, the maximum-K and total cation plant concentration during growth of field vegetable crops. Annals of Botany, v.82, p.871-881, 1998.

LEMAIRE, G.; GASTAL, F.; PLENET, D. Dynamics of N uptake and $\mathrm{N}$ distribution in plant canopies. Use of crop $\mathrm{N}$ status index in crop modelling. In: LEMAIRE, G. (Ed.). Diagnostic procedures for crop N management. Paris: Inra, 1997. p.16-29.

PAULA, A.L. de. Acúmulo de massa seca e nitrogênio durante o crescimento e desenvolvimento da cultura da batata. 2005. 23p. Dissertação (Mestrado) - Universidade Federal de Santa Maria, Santa Maria.

REIS JUNIOR, R.A.; FONTES, P.C.R. Qualidade de tubérculos da batateira em função de doses de adubação potássica. Horticultura Brasileira, v.14, p.170-174, 1996.
REIS JUNIOR, R.A.; FONTES, P.C.R.; NEVES, J.C.L.; SANTOS, N.T. Total soil electrical conductivity and critical soil $\mathrm{K}^{+}$to $\mathrm{Ca}^{2+}$ and $\mathrm{Mg}^{2+}$ ratio for potato crops. Scientia Agricola, v.56, p.985-989, 1999.

REIS JUNIOR, R.A.; MONNERAT, P.H. Exportação de nutrientes nos tubérculos de batata em função de doses de sulfato de potássio. Horticultura Brasileira, v.19, p.360-364, 2001.

SHABALA, S. Regulation of potassium transport in leaves: from molecular to tissue level. Annals of Botany, v.92, p.627-634, 2003.

SOCIEDADE BRASILEIRA DE CIÊNCIA DO SOLO. Comissão de Química e Fertilidade do Solo. Núcleo Regional Sul. Manual de adubação e calagem para os estados do Rio Grande do Sul e Santa Catarina. 10.ed. Porto Alegre, 2004. 400p.

TEDESCO, M.J.; GIANELLO, C.; BISSANI, C.A.; BOHNEN, H.; VOLKWEISS, S.J. Análise de solo, plantas e outros materiais. Porto Alegre: UFRGS, 1995. 173p.

WESTERMANN, D.T.; JAMES, D.W.; TINDALL, T.A.; HURST, R.L. Nitrogen and potassium fertilization of potatoes: sugars and starch. American Potato Journal, v.71, p.433-454, 1994a.

WESTERMANN, D.T.; TINDALL, T.A.; JAMES, D.W.; HURST, R.L. Nitrogen and potassium fertilization of potatoes: yield and specific gravity. American Potato Journal, v.71, p.417-432, 1994b.

YORINORI, G.T. Curva de crescimento e acúmulo de nutrientes pela cultura da batata cv. Atlantic. 2003. 79p. Dissertação (Mestrado) - Escola Superior de Agricultura Luiz de Queiroz, Piracicaba. 